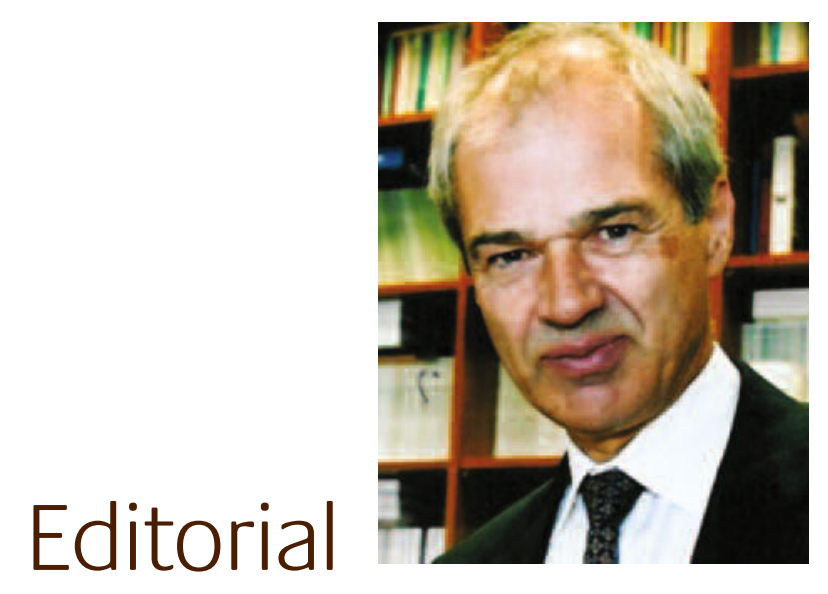

\section{Gold 2006}

As readers of this journal, you will be aware that the international conference "Gold 2006 - New Industrial Applications for Gold' will be held at the campus of the University of Limerick in the West of Ireland from Sunday 3rd to Wednesday 6th September. This meeting, held under the auspices of the World Gold Council, follows on from those held in Vancouver at the end of September in 2003 and in Cape Town in 2001.

It is very evident that much research has been carried out since 2003 on all aspects of the science and applications of gold, judging by the huge increase in the numbers of abstracts submitted. While the Vancouver meeting had a total of 146 presentations and posters, for the Limerick meeting we have been inundated with almost 300 abstracts. As a result, we have been able to select an excellent programme of quality papers for oral presentation (again in four parallel sessions, with two of these devoted largely to catalysis and the others to chemistry and materials and nanotechnology). To ensure we feature all the latest research results, we will hold two extended poster sessions and have introduced a new feature of brief oral presentations of selected poster topics. These 'Quicky Sessions' will enable many poster authors to provide a stimulating introduction to their poster presentations and assist members of the audience to target posters of particular interest.

The selection of the papers for oral presentation at the meeting has been made by a series of sub-committees chaired by the Guest Chairmen: Professor Graham Hutchings and Matasake Haruta for Catalysis, Prof. Antonio Laguna for Chemistry and Professor Michael Cortie for Nanotechnology and Materials. In addition to the regular oral presentations, there will be keynote addresses given by eminent scientists and industrialists, as detailed in the previous issue of Gold Bulletin, 39 (1).

A special Plenary Opening Session will include the Francois Gault Lecture sponsored by the European Federation of Catalysis Societies and given by Professor Graham Hutchings, a presentation on exploiting gold science through the Project AuTEK by Dr Roger Paul of Mintek, a review on the use of gold alloy catalysts in the commercial production of vinyl acetate by Dr Hans Lansink Rotgerink of Degussa, and a lecture on the prehistoric gold of Ireland by Mary Cahill of the National Museum of Ireland. The last of these will also appeal to the guests accompanying attendees.

The campus of the University of Limerick will be known to many as the venue for Europacat $V$ in 2001. Since then, however, there has continued to be a very rapid expansion of its facilities. In particular, several new student villages have been completed which offer high-quality accommodation at a low price for conferences and the sports facilities are exceptional! Coupled with traditional Irish hospitality, this will be a great venue for delegates to GOLD 2006. Needless to say, there is a full social calendar and accompanying persons programme, the latter including a visit to the National Museum to view, under Dr. Mary Cahill's expert guidance, their wonderful, unique collection of prehistoric gold.

We look forward to greeting you in Limerick and participating in what promises to be a most enjoyable and successful conference. For full details of the programme, how to get to Limerick and even how to arrange a holiday in conjunction with your visit, see www.gold2006.com

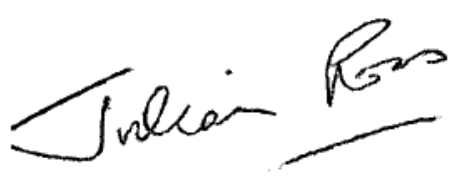

Julian Ross

Professor Ross is based at the University of Limerick and is technical co-ordinator, GOLD 2006.

Editor's note: The oral presentations and many posters will be published in special GOLD 2006 conference editions of top journals, including Gold Bulletin. 